\title{
Fetuin-A level in type 2 diabetic patients: relation to microvascular complications
}

\author{
Nehal H. Al-Said ${ }^{a}$, Fatma M. Taha ${ }^{\mathrm{b}}$, Ghada M. Abdel-Aziz ${ }^{\mathrm{c}}$, \\ Marwa S. Abdel-Tawabc
}

\begin{abstract}
Departments of anternal Medicine, ${ }^{b}$ Medical Biochemistry, Faculty of Medicine, Cairo University, Cairo, 'Department of Medical Biochemistry, Faculty of Medicine, Beni-Suef University, Beni Suef, Egypt

Correspondence to Marwa S. Adbel-Tawab, $\mathrm{PhD}$ of Medical Biochemistry and Molecular Biology, Department of Medical Biochemistry, Faculty of Medicine, Beni-Suef University, 6 El Maghraby Street, Elwasta, Beni Suef, 51162, Egypt.

e-mail: marwa.amar@med.bsu.edu.eg
\end{abstract}

Received 22 April 2018

Accepted 5 May 2018

The Egyptian Journal of Internal Medicine 2018, 30:121-130

\begin{abstract}
Background
Fetuin-A is a hepatic secretory protein that binds to insulin receptors and inhibits insulin resistance (IR) kinase activity as well as IR autophosphorylation in vivo and in vitro.

Aim

This study aimed to investigate fetuin-A levels in patients with type 2 diabetes mellitus (T2DM) and their relation to microvascular complications.

Patients and methods

This descriptive study was conducted on 160 patients. Group 1 included $(n=40)$ diabetic patients without microvascular complications, group $2(n=40)$ included diabetic patients with nephropathy, group $3(n=40)$ included diabetic patients with retinopathy, and group 4 represented $(n=40)$ healthy control. Serum fetuin-A and insulin were measured by enzyme-linked immunosorbent assay. Glucose was measured, and homeostasis model assessment for IR (HOMA-IR) was estimated. Results

Fetuin-A levels were significantly higher in all T2DM groups compared with controls. There was a significant positive correlation between fetuin-A, insulin, and HOMA-IR in all studied groups. There was a significant positive correlation between fetuin-A and some of metabolic syndrome criteria in all diabetic patients. There were high significant increases in the mean levels of fetuin-A, insulin, and HOMA-IR in the diabetic patients with nephropathy group than other groups. There was a nonsignificant increase in fetuin-A levels in diabetic patients with retinopathy than the diabetics without microvascular complications.
\end{abstract}

\section{Conclusion}

Fetuin-A may be used as a marker for microvascular complications in T2DM, especially the diabetic nephropathy. Antifetuin drugs may be invented to delay diabetic microvascular complications.

\section{Keywords:}

diabetes mellitus, diabetic nephropathy and diabetic retinopathy, fetuin- $A$, insulin

Egypt J Intern Med 30:121-130

(c) 2018 The Egyptian Journal of Internal Medicine

$1110-7782$

\section{Introduction}

Diabetes mellitus (DM) has routinely been described as a metabolic disorder characterized by hyperglycemia that develops because of defects in insulin secretion, insulin action, or both. Type 2 diabetes mellitus (T2DM) encompasses individuals who have insulin resistance (IR) and usually relative (rather than absolute) insulin deficiency [1]. T2DM has emerged as a major worldwide public health problem; according to Diabetes Atlas (7th ed.), the global prevalence of diabetes is estimated at 415 million (8.8\%), which is predicted to increase to 642 million in the next 25 years [2].

Diverse biomarkers were studied for identifying of patients with T2DM at microvascular and macrovascular risk. Most of these markers are inflammatory, metabolic, or procoagulant molecules, indicating an unfavorable metabolic and vascular repute in patients with T2DM. However, the different biomarkers display huge variations in hazard prediction depending on metabolic repute and disease severity of the study groups [3]. Posted records suggest that most novel biomarkers do not enhance hazard prediction while brought to fashions based totally on traditional hazard scores [4]. Yet, associations of novel biomarkers such as fetuin-A with metabolic markers or complications do assist to understand their position within the pathophysiology of the vascular disease [5].

Fetuin-A [also referred to as $\alpha-2$ Heremans Schmid glycoprotein (AHSG)] is a multifunctional glycoprotein which is exclusively secreted from the hepatocytes in human [6]. For a long time, fetuin-A

\footnotetext{
This is an open access journal, and articles are distributed under the terms of the Creative Commons Attribution-NonCommercial-ShareAlike 4.0 License, which allows others to remix, tweak, and build upon the work non-commercially, as long as appropriate credit is given and the new creations are licensed under the identical terms.
} 
has been considered to play a critical role in the safety from vascular calcification by solubilizing calcium and phosphorus in serum [7]. It also became pronounced that fetuin-A could inhibit insulin receptor substrate-1 and stimulated a lower-grade inflammation [8], which led to IR [9]. Epidemiological research confirmed that serum fetuin-A became associated with IR and its comorbidities, including metabolic syndrome (MetS) [10] and T2DM [11].

In mice with knockout of fetuin-A, feeding of a mineral/vitamin D-rich food regimen led to arterial or soft-tissue calcification or both [7]. In human, so far, the available facts have been inconsistent. Lower fetuin-A ranges are associated with mortality and cardiovascular disorder occasions in cohorts with end-stage renal disease [12], whereas a populationbased study linked excessive plasma fetuin-A to an increased hazard of myocardial infarction and ischemic stroke [13].

This study aimed to investigate fetuin-A levels in patients with T2DM and their relation to microvascular complications [diabetic retinopathy (DR) and diabetic nephropathy].

\section{Patients and methods}

This descriptive study was conducted in Medical Biochemistry Department, Faculty of Medicine, Cairo University, in the period between September 2015 and May 2016. This study was approved by the Ethical Committee of Kasr Al-Ainy Medical Hospital and was conducted in accordance with the principle of Helsinki Declaration II. A written informed consent was obtained from each participant. A total of 60 patients with T2DM were selected from the outpatients and the inpatients section of the Internal Medicine Department at Beni-Suef University Hospital. They were diagnosed as diabetic patients according to the American Diabetes Association criteria [14]. Moreover, 40 (age and sex matched) apparently healthy individuals were selected from workers in Medical Biochemistry Department, Beni-Suef University. Group 1 included 40 patients with T2DM without complications (with a mean age of 59.8 years). Group 2 included 40 patients with T2DM with nephropathy (with a mean age of 57.0 years). Group 3 included 40 patients with T2DM with retinopathy (with a mean age of 60.0 years). Group 4 included 40 healthy age-matched and sex-matched control volunteers.

\section{Exclusion criteria}

Patients having serum creatinine above $2.5 \mathrm{mg} / \mathrm{dl}$, liver disorders, chronic inflammatory disease, infectious disease, a history of cardiovascular disease, malignant neoplasm, type 1 diabetes, other renal disease by urinary sediments and medical records, taking calcium or vitamin D supplementation, and taking insulin-sensitizing treatment such as pioglitazone were excluded. All participants were subjected to the following: full medical history and full clinical examination; anthropometric measurement including waist and hip circumference in $\mathrm{cm}$, weight in $\mathrm{kg}$, and height in $\mathrm{cm}$; BMI calculated as weight in kilograms divided by square of height in meters [15]; fundus examination to assess DR; estimation of biochemical variables (fasting and postprandial glucose, total cholesterol, triglycerides, low-density lipoprotein-cholesterol (LDL-c), highdensity lipoprotein-cholesterol (HDL-c), urea, creatinine clearance, and 24-h urinary protein) after an overnight fasting of at least $10 \mathrm{~h}$; and estimation of serum levels of fetuin- $A$ and insulin using enzyme-linked immunosorbent assays. Homeostasis model assessment for IR (HOMA-IR) values were calculated based on fasting value of plasma glucose and insulin according HOMA model formula: HOMA-IR=fasting insulin $(\mathrm{mlU} / \mathrm{l}) \times$ fasting glucose $(\mathrm{mg} / \mathrm{dl}) / 405$. IR was arbitrarily considered altered when it wasmore than $<2$ [16].

Estimation of serum fetuin-A was done by using enzyme immunoassay kit procured from BioVendor Laboratory Medicine Inc. (Brno, Czech Republic). Estimation of insulin was done by enzyme-linked immunosorbent assay kit procured from Monobind Inc. (Lake Forest, California, USA). To estimate the fasting blood glucose and postprandial blood glucose, plasma glucose was measured by the glucose oxidase method using a commercially available kit supplied by Diamond, Egypt. Estimation of total cholesterol was estimated by Quantitative-Enzymatic-Colorimetric determi- nation of total cholesterol though a serum kit, which was provided by StainBio Company (Texas, USA) [17]. Estimation of triglycerides was done by QuantitativeEnzymatic-Colorimetric determination of triglycerides through a serum kit GPO-POD provided by Diamond Company (Cairo, Egypt) [18]. Estimation of HDL-c was estimated by Quantitative-Enzymatic-Colorimetric determination of HDL-c through a serum kit, which was provided by StainBio Company [19]. Estimation of LDL-c value was calculated using Friedewald equation [20]: LDL=total cholesterol-HDL-TG/5. Estimation of creatinine was done by kinetic method according to modified Jaffe method kit, which was provided by StainBio Company [21]. Estimation of urea was done by an enzymatic micromethod according to modified 
urease method kit, which was provided by StainBio Company [22]. To estimate urinary protein, 24-h urine sample was collected by instructing participants to begin collection immediately after completion of first voiding in morning and to collect all urine into same container for $24 \mathrm{~h}$, including final void at completion of $24-\mathrm{h}$ period [23]. Urinary total protein was analyzed using Thermo microprotein kit (Thermo Fisher Scientific, Waltham, Massachusetts, USA). Urinary excretion of protein is normally less than $0.15 \mathrm{~g} / 24 \mathrm{~h}(150 \mathrm{mg} / 24 \mathrm{~h})$. The proteinuria of at least $300 \mathrm{mg} / \mathrm{dl}$ in $24-\mathrm{h}$ urine sample was considered as significant proteinuria [24].

\section{Statistical analysis}

Analysis of data was performed using SPSS 21 for Windows SPSS (IBM Corp., Released 2013, IBM SPSS Statistics for Windows, Version 21.0, Armonk, NY, USA). Description of variables was presented as follows: description of qualitative variables was in the form of numbers $(n)$ and percentages (\%). Comparison between quantitative variables was carried out by student $t$-test of two independent samples. Results were expressed in the form of $P$ values.
Comparison between nonparametric quantitative variables was carried out by Mann-Whitney $U$-test. Kruskal-Wallis test was used when comparing between more than two groups of independent variables. Results were expressed in the form of $P$ values. Comparison between qualitative variables was carried out by $\chi^{2}$-test. Fisher's exact test was used instead of $\chi^{2}$-test when one expected cell or more were 5 or less. Binary correlation was carried out by Spearman's correlation test. Results were expressed in the form of correlation coefficient $(R)$ and $P$ values. The following points are the accepted guidelines for interpreting the correlation coefficient: 0 indicates no linear relationship and +1 indicates a perfect positive linear relationship: as one variable increases in its values, the other variable also increases in its values by an exact linear rule.

\section{Results}

Table 1 showed the demographic, laboratory, and measured data of the studied groups. A highly significant increase was seen in the mean level of systolic blood pressure (SBP), diastolic blood

Table 1 Demographic and laboratory data of the studied groups $(N=40)$

\begin{tabular}{|c|c|c|c|c|}
\hline Parameters & $\begin{array}{c}\text { Group } 1 \text { diabetic without } \\
\text { complications }\end{array}$ & $\begin{array}{c}\text { Group } 2 \text { diabetic } \\
\text { nephropathy group }\end{array}$ & $\begin{array}{c}\text { Group } 3 \text { diabetic retinopathy } \\
\text { group }\end{array}$ & $\begin{array}{c}\text { Group } 4 \text { contro } \\
\text { group }\end{array}$ \\
\hline Age & $59.8 \pm 6.3$ & $57.0 \pm 9.6$ & $60.0 \pm 8.3$ & $57.9 \pm 7.3$ \\
\hline \multicolumn{5}{|l|}{$\operatorname{Sex}[n(\%)]$} \\
\hline Male & $5(25)$ & $5(25)$ & $6(30)$ & $8(40)$ \\
\hline Femal & $15(75)$ & $15(75)$ & $14(70)$ & $12(60)$ \\
\hline $\begin{array}{l}\text { Disease duration } \\
\text { (years) }\end{array}$ & $12.1 \pm 2.8$ & $14.2 \pm 3.5(\mathrm{c})$ & $11.8 \pm 4.2$ & - \\
\hline $\mathrm{SBP}(\mathrm{mmHg})$ & $140.5 \pm 11.6(a)^{*}$ & $142.3 \pm 16.7(a)^{\star}$ & $145.5 \pm 11.2(a)^{*}$ & $119.8 \pm 8.0$ \\
\hline DBP $(\mathrm{mmHg})$ & $91.5 \pm 6.5(a)^{*}$ & $89.5 \pm 12.6(a)^{\star}$ & $94.8 \pm 8.7(a)^{\star}$ & $78.3 \pm 3.7$ \\
\hline $\begin{array}{l}\text { Waist circumference } \\
(\mathrm{cm})\end{array}$ & $87.2 \pm 10.3(a)^{*}$ & $94.6 \pm 5.0(a)^{\star}(b)^{\star}(c)$ & $89.4 \pm 4.9(a)^{*}$ & $72.6 \pm 6.2$ \\
\hline $\begin{array}{l}\text { Hip circumference } \\
(\mathrm{cm})\end{array}$ & $96.8 \pm 7.7(a)^{\star}$ & $103.3 \pm 4.7(a)^{\star}(b)^{\star}(C)^{\star}$ & $98.0 \pm 4.0(\mathrm{a})^{*}$ & $85.3 \pm 6.9$ \\
\hline $\mathrm{W} / \mathrm{H}$ ratio & $0.9 \pm 0.1(a)^{\star}$ & $0.9 \pm 0.0(a)^{*}$ & $0.9 \pm 0.0(a)^{*}$ & $0.8 \pm 0.0$ \\
\hline BMI $\left(\mathrm{kg} / \mathrm{m}^{2}\right)$ & $32.9 \pm 5.4(a)^{*}$ & $34.0 \pm 4.5(\mathrm{a})^{*}$ & $32.5 \pm 4.8(a)^{*}$ & $25.5 \pm 2.2$ \\
\hline TAG (mg/dl) & $146.0 \pm 11.1$ & $208.9 \pm 49.1(a)^{\star}(b)(c)^{*}$ & $170.4 \pm 36.3(a)^{\star}(b)$ & $137.4 \pm 9.4$ \\
\hline Cholesterol (mg/dl) & $173.6 \pm 24.3$ & $220.0 \pm 27.7(a)^{\star}(b)^{\star}(c)^{*}$ & $184.7 \pm 32.0(a)$ & $163.9 \pm 10.9$ \\
\hline HDL-c (mg/dl) & $61.7 \pm 7.1$ & $50.7 \pm 11.3(a)^{\star}(b)^{\star}$ & $50.9 \pm 14.5(a)^{\star}(b)^{\star}$ & $62.4 \pm 5.6$ \\
\hline LDL-c (mg/dl) & $105.2 \pm 28.2$ & $156.6 \pm 35.9(a)^{\star}(b)^{\star}(c)^{\star}$ & $126.1 \pm 40.2(a)^{\star}(b)$ & $95.4 \pm 13.7$ \\
\hline $\begin{array}{l}\text { Urinary protein }(\mathrm{mg} / \\
24 \mathrm{~h})\end{array}$ & $135.2 \pm 13.8$ & $690.8 \pm 275.1(b)^{\star}(c)^{*}$ & $131.1 \pm 21.1$ & - \\
\hline Creatinine (mg/dl) & $0.8 \pm 0.2$ & $1.9 \pm 0.3(\mathrm{a})^{\star}(\mathrm{b})^{\star}(\mathrm{c})^{\star}$ & $0.7 \pm 0.3$ & $0.7 \pm 0.2$ \\
\hline Urea (mg/dl) & $35.4 \pm 4.3$ & $87.2 \pm 23.2(a)^{\star}(b)^{\star}(c)^{\star}$ & $35.8 \pm 4.8$ & $33.4 \pm 5.7$ \\
\hline FBG (mg/dl) & $249.3 \pm 58.2(a)^{*}(\mathrm{c})^{*}$ & $184.0 \pm 23.4(a)^{\star}(b)^{\star}$ & $165.5 \pm 28.0(a)^{*}$ & $87.4 \pm 11.3$ \\
\hline PPBG (mg/dl) & $318.9 \pm 73.9(a)^{\star}$ & $379.9 \pm 81.9(a)^{\star}(b)^{\star}$ & $348.6 \pm 82.5(a)^{*}$ & $111.0 \pm 11.7$ \\
\hline Insulin $(\mu \mathrm{IU} / \mathrm{ml})$ & $15.1 \pm 3.8(a)^{\star}$ & $23.0 \pm 5.8(a)^{\star}\left(b^{\star}(c)^{\star}\right.$ & $17.6 \pm 7.0(a)^{\star}$ & $7.6 \pm 2.2$ \\
\hline HOMA-IR & $9.2 \pm 2.7(\mathrm{a})^{\star}(\mathrm{c})$ & $10.5 \pm 3.4(a)^{\star}(\mathrm{c})^{*}$ & $7.4 \pm 3.7(a)^{\star}$ & $1.6 \pm 0.6$ \\
\hline Fetuin-A (mg/dl) & $254.8 \pm 45.6(a)^{*}$ & $323.8 \pm 50.8(a)^{\star}(b)^{\star}(c)^{*}$ & $259.7 \pm 57.4(a)^{*}$ & $159.5 \pm 33.6$ \\
\hline
\end{tabular}

Letter (a) denotes a significant difference as compared with group 4, letter (b) denotes a significant difference as compared with group 1, letter (c) denotes a significant difference as compared with group 3. Results are expressed as mean $\pm S D$. FBG, fasting blood sugar; HDLc, high-density lipoprotein-cholesterol; HOMA-IR, homeostasis model of assessment-insulin resistance; LDL-c, low-density lipoproteincholesterol; PPBG, postprandial blood sugar; TAG, triacyl glycerides. *High significance $(P<0.01)$ 
pressure $(\mathrm{DBP})$, waist-hip ratio $(\mathrm{W} / \mathrm{H})$ ratio, and $\mathrm{BMI}$ in diabetic patients without complications group (group 1), diabetic nephropathy group (group 2), and DR group (group3) compared with the control group (group 4). A highly significant increase was seen in the mean level of waist circumference and hip circumference in diabetic nephropathy group (group 2) compared with both diabetic without complications group (group 1) and DR group (group 3). There was a significant increase in the mean level of the disease duration in diabetic nephropathy group (group 2) compared with the DR group (group 3). No significant differences were detected in the mean levels of age and sex between the studied groups.

A significant increase was seen in the mean level of triacylglycerol (TAG), cholesterol, and LDL-c in DR group (group 3) versus both control group (group 4) and diabetic without complications group (group 1). A highly significant increase was seen in the mean levels of TAG, cholesterol, LDL-c, 24-h urinary protein, creatinine, and urea in diabetic nephropathy group (group 2) versus other groups.
A highly significant decrease was seen in the mean level of HDL-c in diabetic nephropathy group (group 2) versus both diabetic without complications group (group 1) and control group (group 4). A highly significant decrease was seen in the mean level of HDL-c in DR group (group 3) versus both diabetic without complications group (group 1) and control group (group 4). No significant differences were detected in laboratory data between the diabetic without complications group (group 1) versus the control group (group 4). A significant increase was seen in the mean levels of fasting blood glucose (FBG) and HOMA-IR (Fig. 1) in diabetic without complications group (group 1) versus the DR group (group 3). A highly significant increase was seen in the mean levels of FBG, postprandial blood glucose (PPBG), insulin (Fig. 2), and fetuin-A (Fig. 3) in the diabetic nephropathy group (group 2) versus the diabetic without complications group (group 1). A highly significant increase was seen in the mean levels of insulin, HOMA-IR, and fetuin-A in diabetic nephropathy group (group 2) versus the DR group (group 3). No significant differences were

\section{Figure 1}

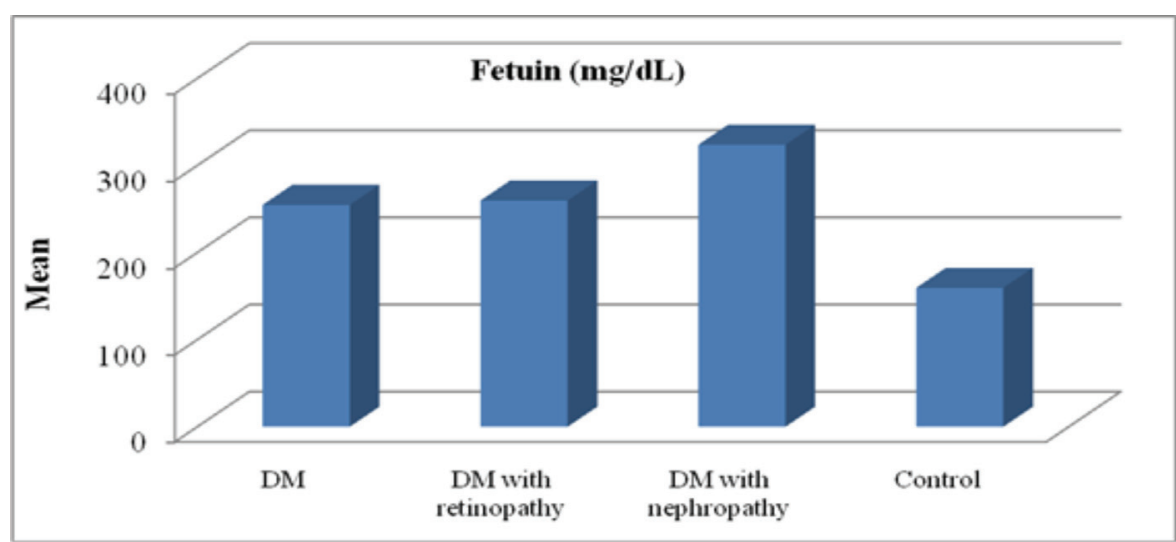

The mean levels of serum homeostasis model assessment for insulin resistance (HOMA-IR) in the studied groups. DM, diabetes mellitus.

Figure 2

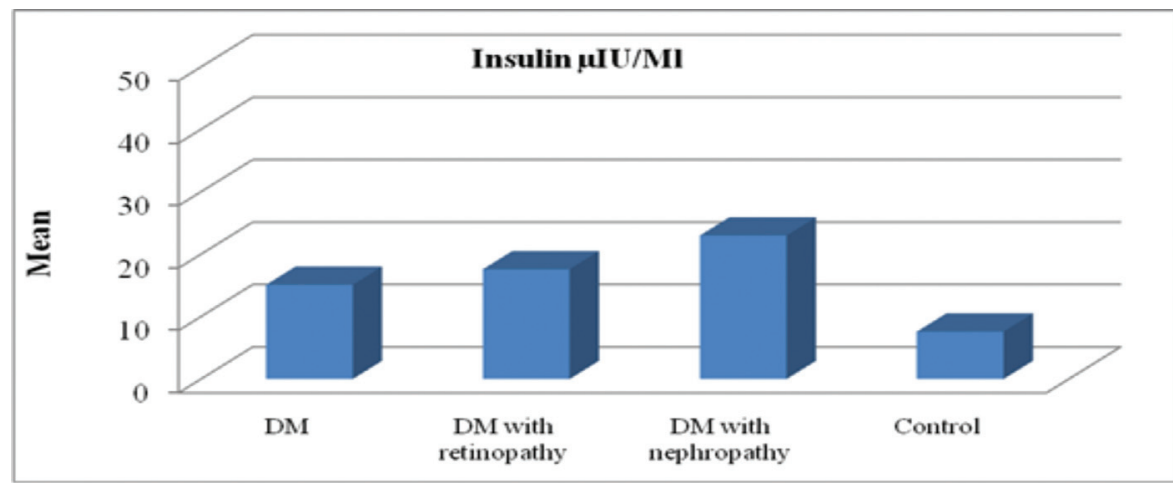

The mean levels of serum insulin in the studied groups. DM, diabetes mellitus. 
detected in the mean levels of PPBG, insulin, and fetuin-A between diabetic without complications group (group 1) and DR group (group 3). No significant differences were detected in the mean levels of FBG and PPBG between diabetic nephropathy group (group 2) and DR group (group 3). No significant differences were detected in the mean level of HOMA-IR between the diabetic without complications group (group 1) and diabetic nephropathy group (group 2).

Table 2 showed the correlations of serum level of fetuin-A with data of the studied groups. In the diabetic without complications group (group 1), there was a significant positive correlation between fetuin-A and BMI $(r=0.59, \quad P=0.006),$,$\quad SBP$ $(r=0.77, P<0.001)$, DBP $(r=0.55, P=0.012)$, waist circumference $(r=0.72, \quad P<0.001), \quad \mathrm{W} / \mathrm{H}$ ratio $(r=0.78, \quad P<0.001),$,$\quad TAG \quad(r=0.47, \quad P=0.038)$, cholesterol $\quad(r=0.66, \quad P=0.004), \quad$ LDL-c $\quad(r=0.68$, $P=0.001)$ insulin $(r=0.61, \quad P<0.001$, Fig. 4), HOMA-IR $(r=0.76, P<0.001$, Fig. 5), and the duration of the disease $(r=0.7, P<0.001)$. There was a significant negative correlation between fetuin- $A$ and HDL-c $(r=-0.45, P=0.046)$.

In the diabetic nephropathy group (group 2), there was a significant positive correlation between fetuin-A and SBP $(r=0.47, P=0.037), \mathrm{DBP}(r=0.54, P=0.015)$, waist circumference $(r=0.65, \quad P=0.002), \quad$ hip circumference $(r=0.63, P=0.003)$, TAG $(r=0.60$, $P=0.005)$, LDL-c $(r=0.47, P=0.038), 24-h$ urinary protein ( $r=0.51, P=0.023$, Fig. 6), FBG $(r=0.60$, $P=0.006)$, insulin $(r=0.69, P=0.001)$, and HOMAIR $(r=0.78, P<0.001)$.

In the DR group (group 3), there was a significant positive correlation between fetuin-A and BMI $(r=0.77, P<0.001)$, SBP $(r=0.52, P=0.019)$, DBP $(r=0.58, \quad P=0.007)$, waist circumference $(r=0.45$, $P=0.046), \mathrm{W} / \mathrm{H}$ ratio $(r=0.62, P=0.003), \mathrm{TAG}$ $(r=0.53, P=0.016)$, cholesterol $(r=0.61, P=0.004)$, LDL-c $(r=0.62, P=0.004)$, FBG $(r=0.51, P=0.023)$, insulin $(r=0.84, P<0.001)$, HOMA-IR $(r=0.85$, $P<0.001)$, and the duration of the disease $(r=0.7$, $P=0.001)$.

Figure 3

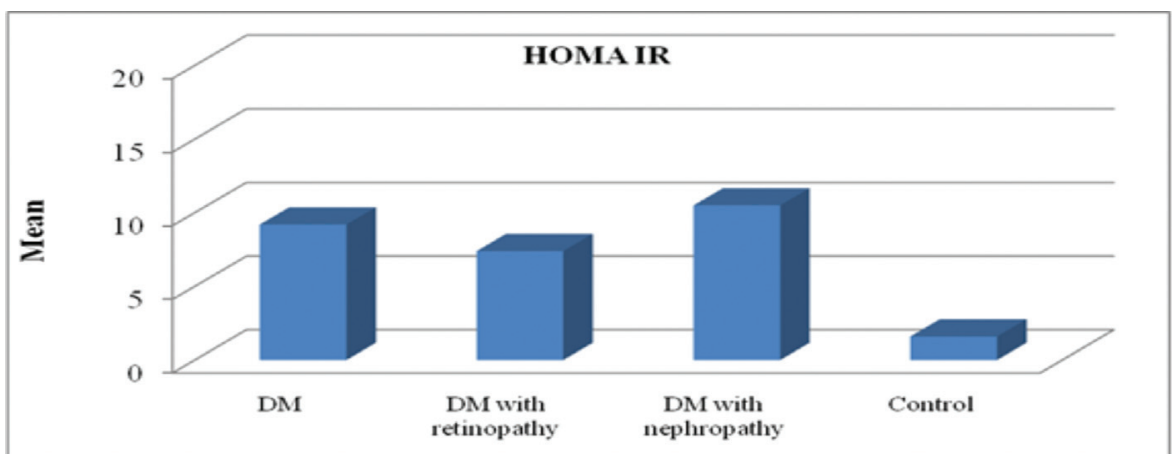

The mean levels of serum fetuin-A in the studied groups. DM, diabetes mellitus.

Figure 4

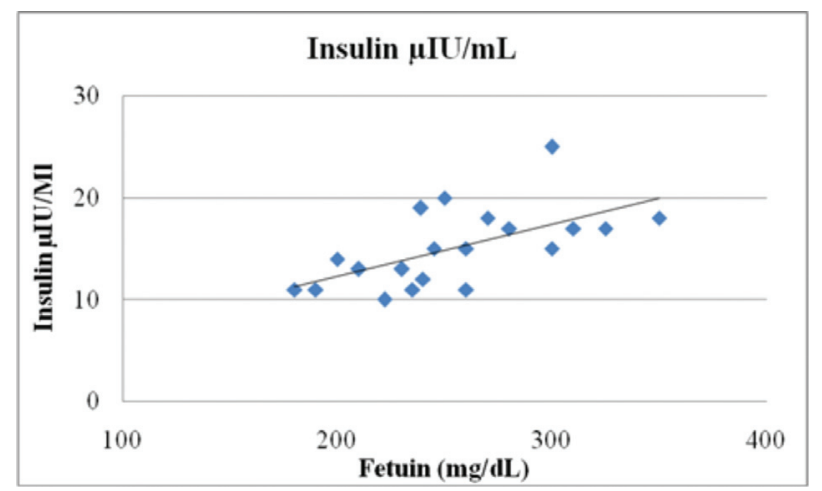

Correlation between fetuin-A $(\mathrm{mg} / \mathrm{dl})$ and insulin in diabetic without complications group (group 1) $(r=0.61, P<0.001)$.
Figure 5

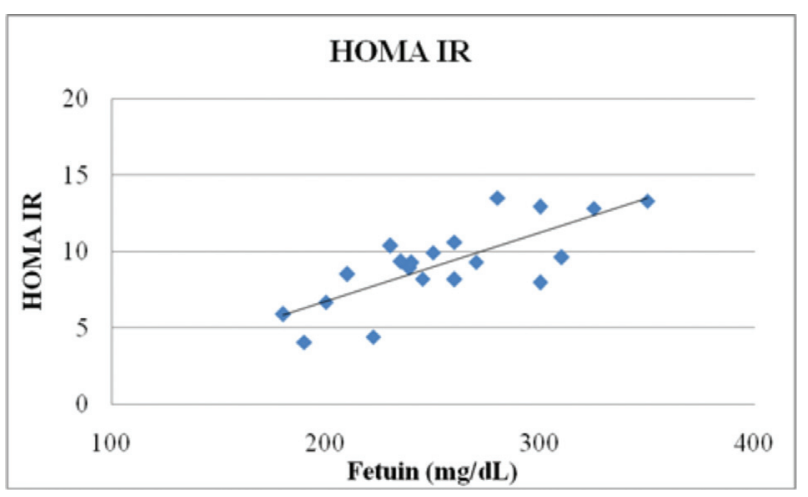

Correlation between fetuin-A (mg/dl) and homeostasis model assessment for insulin resistance (HOMA-IR) in diabetic without complications group (group 1) $(r=0.76, P<0.001)$. 
Table 2 Correlation between fetuin-A $(\mathrm{mg} / \mathrm{dl})$ and the data of the studied groups $(\mathrm{N}=40)$

\begin{tabular}{|c|c|c|c|c|}
\hline Parameters & $\begin{array}{l}\text { Group } 1 \text { diabetic without } \\
\text { complications }\end{array}$ & $\begin{array}{c}\text { Group } 2 \text { diabetic nephropathy } \\
\text { group }\end{array}$ & $\begin{array}{c}\text { Group } 3 \text { diabetic retinopathy } \\
\text { group }\end{array}$ & $\begin{array}{l}\text { Group } 4 \text { control } \\
\text { group }\end{array}$ \\
\hline \multicolumn{5}{|l|}{ Age (years) } \\
\hline$r$ & -0.42 & -0.38 & -0.34 & -0.09 \\
\hline$P$ & 0.065 & 0.100 & 0.137 & 0.695 \\
\hline \multicolumn{5}{|l|}{ BMI $\left(\mathrm{kg} / \mathrm{m}^{2}\right)$} \\
\hline$r$ & $0.59^{\star \star}$ & 0.35 & $0.77^{\star \star}$ & $0.79^{\star \star}$ \\
\hline$P$ & 0.006 & 0.134 & $<0.001$ & $<0.001$ \\
\hline \multicolumn{5}{|c|}{$\mathrm{SBP}(\mathrm{mmHg})$} \\
\hline$r$ & $0.77^{\star \star}$ & $0.47^{\star}$ & $0.52^{\star}$ & 0.17 \\
\hline$P$ & $<0.001$ & 0.037 & 0.019 & 0.470 \\
\hline \multicolumn{5}{|c|}{ DBP (mmHg) } \\
\hline$r$ & $0.55^{\star}$ & $0.54^{\star}$ & $0.58^{\star *}$ & -0.08 \\
\hline$P$ & 0.012 & 0.015 & 0.007 & 0.752 \\
\hline \multicolumn{5}{|c|}{ Waist circumference $(\mathrm{cm})$} \\
\hline$r$ & $0.72^{* \star}$ & $0.65^{\star \star}$ & $0.45^{\star}$ & $0.68^{* *}$ \\
\hline$P$ & $<0.001$ & 0.002 & 0.046 & 0.001 \\
\hline \multicolumn{5}{|c|}{ Hip circumference $(\mathrm{cm})$} \\
\hline$r$ & 0.05 & $0.63^{* *}$ & 0.29 & $0.56^{\star}$ \\
\hline$P$ & 0.841 & 0.003 & 0.223 & 0.010 \\
\hline \multicolumn{5}{|c|}{ Waist-hip ratio } \\
\hline$r$ & $0.78^{\star \star}$ & 0.13 & $0.62^{\star \star}$ & 0.27 \\
\hline$P$ & $<0.001$ & 0.586 & 0.003 & 0.245 \\
\hline \multicolumn{5}{|l|}{ TAG (mg/dl) } \\
\hline$r$ & $0.47^{\star}$ & $0.60^{* *}$ & $0.53^{*}$ & $0.52^{\star}$ \\
\hline$P$ & 0.038 & 0.005 & 0.016 & 0.019 \\
\hline \multicolumn{5}{|c|}{ Cholesterol (mg/dl) } \\
\hline$r$ & $0.66^{* *}$ & 0.34 & $0.61^{* *}$ & 0.23 \\
\hline$P$ & 0.001 & 0.138 & 0.004 & 0.333 \\
\hline \multicolumn{5}{|c|}{ HDL-c (mg/dl) } \\
\hline$r$ & $-0.45^{\star}$ & -0.31 & -0.41 & -0.04 \\
\hline$P$ & 0.046 & 0.185 & 0.070 & 0.865 \\
\hline \multicolumn{5}{|c|}{ LDL-c (mg/dl) } \\
\hline$r$ & $0.68^{\star *}$ & $0.47^{\star}$ & $0.62^{* \star}$ & 0.20 \\
\hline$P$ & 0.001 & 0.038 & 0.004 & 0.403 \\
\hline \multicolumn{5}{|c|}{ Urinary protein $(\mathrm{mg} / 24 \mathrm{~h})$} \\
\hline$r$ & 0.20 & $0.51^{*}$ & 0.18 & - \\
\hline$P$ & 0.403 & 0.023 & 0.439 & - \\
\hline \multicolumn{5}{|c|}{ Creatinine $(\mathrm{mg} / \mathrm{dll})$} \\
\hline$r$ & -0.31 & 0.02 & 0.07 & 0.00 \\
\hline$P$ & 0.191 & 0.929 & 0.760 & 0.984 \\
\hline \multicolumn{5}{|l|}{ Urea (mg/dl) } \\
\hline$r$ & -0.10 & 0.02 & 0.10 & -0.25 \\
\hline$P$ & 0.662 & 0.920 & 0.684 & 0.282 \\
\hline \multicolumn{5}{|l|}{$\mathrm{FBG}(\mathrm{mg} / \mathrm{dl})$} \\
\hline$r$ & 0.32 & $0.60^{* *}$ & $0.51^{*}$ & 0.39 \\
\hline$P$ & 0.166 & 0.006 & 0.023 & 0.090 \\
\hline \multicolumn{5}{|c|}{ PPBG (mg/dl) } \\
\hline$r$ & -0.06 & -0.25 & -0.01 & 0.08 \\
\hline$P$ & 0.787 & 0.290 & 0.970 & 0.727 \\
\hline \multicolumn{5}{|c|}{ Insulin $(\mu \mathrm{IU} / \mathrm{ml})$} \\
\hline$r$ & $0.69^{\star \star}$ & $0.69^{\star \star}$ & $0.84^{\star \star}$ & $0.72^{\star \star}$ \\
\hline$P$ & 0.001 & 0.001 & $<0.001$ & $<0.001$ \\
\hline \multicolumn{5}{|l|}{ HOMA-IR } \\
\hline$r$ & $0.76^{\star \star}$ & $0.78^{\star \star}$ & $0.85^{\star \star}$ & $0.72^{\star \star}$ \\
\hline$P$ & $<0.001$ & $<0.001$ & $<0.001$ & $<0.001$ \\
\hline Duration of $t$ & sease (years) & & & \\
\hline$r$ & $0.7^{\star \star}$ & 0.2 & $0.7^{\star \star}$ & - \\
\hline$P$ & $<0.001$ & 0.405 & 0.001 & - \\
\hline
\end{tabular}

DBP, diastolic blood pressure; FBG, fasting blood sugar; HDL-c, high-density lipoprotein cholesterol; HOMA-IR, homeostasis model of assessment-insulin resistance; LDL-c, low-density lipoprotein cholesterol; PPBG, postprandial blood sugar; SBP, systolic blood pressure; TAG, triacyl glycerides; W/H ratio, waist-hip ratio. ${ }^{* *}$ Correspondence to Correlation is significant, $P<0.05$ level. ${ }^{*}$ Correlation is significant, $P<0.01$ level. 
Figure 6

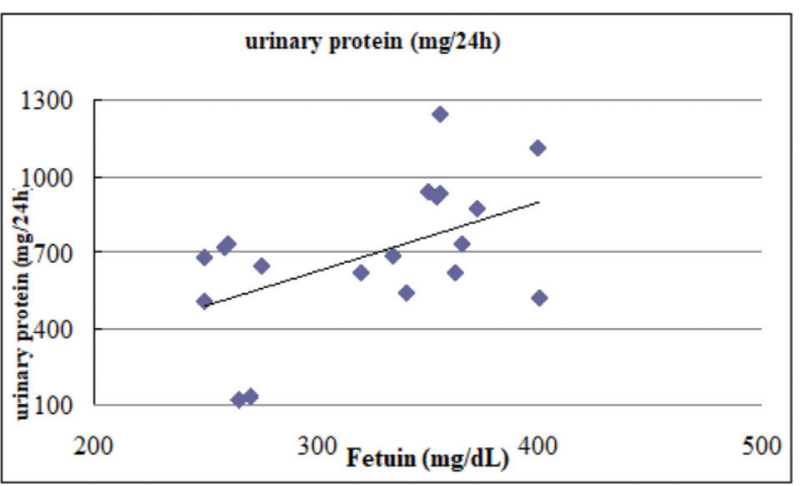

Correlation between fetuin- $\mathrm{A}(\mathrm{mg} / \mathrm{dl})$ and $24-\mathrm{h}$ urinary protein in diabetic nephropathy group (group 2) $(r=0.51, P=0.023)$.

In the control group (group 4), there was a significant positive correlation between fetuin-A and BMI $(r=0.79, \quad P<0.001)$, waist circumference $(r=0.68$, $P=0.001)$, hip circumference $(r=0.56, \quad P=0.010)$, TAG $(r=0.52, P=0.019)$, insulin $(r=0.72, P<0.001)$, and HOMA-IR $(r=0.72, P<0.001)$.

\section{Discussion}

The gene encoding fetuin-A is located on chromosome $3 q 27$, the chromosomal location that was formerly mapped as a T2DM and MetS susceptibility locus [25]. It was well known that IR is the underlying mechanism of T2DM [26].

In this study, we evaluated the associations of parameters of microvascular disease in patients with T2DM, DR, and diabetic nephropathy as the degree of protein excretion and renal function (serum urea and serum creatinine) with fetuin-A. This study included four main groups: T2DM without complications (group 1), diabetic nephropathy (group 2), DR patients (group 3), and normal healthy control (group 4). Of the 160 included participants, 98 were females and 62 were males, and their ages ranged between 47 and 76 years. There were no significant differences detected in the mean levels of age and sex between the studied groups.

We observed a highly significant increase in the mean levels of fetuin-A in all diabetic groups $(1,2,3)$ than the control group (4), and there was a significant positive correlation between fetuin- $A$, insulin, and HOMA-IR in all studied groups.

Our results coincided with Guo et al. [27] who showed that higher circulating fetuin-A levels were associated with increased risk of T2DM.
Sujana et al [28] agreed with us because they concluded that higher fetuin-A levels are associated with incident T2DM in both male and female individuals. They added that increase in fetuin-A levels was independent of subclinical inflammation, adiponectin, and liver fat content.

Pinnaduwage et al. [29] agreed with us as they concluded that circulating hepatic markers, particularly fetuin-A, track with changes in insulin sensitivity and $\beta$-cell function, supporting a pathophysiologic basis in their prediction of diabetic risk.

Roshanzamir et al. [30] concurred with our results as they showed a significant relationship between the fetuin-A levels with T2DM risk.

In accordance with our results, Yin and colleagues suggested that the plasma fetuin-A levels may be associated with macroangiopathies in patients with new-onset T2DM. Therefore, detecting early plasma fetuin-A levels in patients with new-onset T2DM provides an opportunity to intervene in the formation of carotid artery disease in diabetic patients and deliver timely treatment for the prevention of diabetic vascular disease [31].

$\mathrm{Ou}$ et al. [32] agreed with us because they suggested that fetuin-A may further aggravate increased arterial stiffness in diabetes.

We concur with Iyidir et al. who indicated that serum fetuin-A concentrations are increased in women with gestational DM and decrease after delivery. Therefore, fetuin-A might have a role in the development of IR and the metabolic changes in gestational DM [33].

In accordance with these results, a previous study by $\mathrm{Ix}$ et al. [11] found that serum fetuin-A was related to incident diabetes, independent of other markers of IR.

In accordance with our results, Song et al. showed that serum fetuin-A concentrations have been drastically higher in T2DM patients than subjects with normal glucose tolerance and impaired glucose tolerance, but they disagreed with us regarding the correlation between fetuin-A and IR, as they showed that higher fetuin-A concentrations had been independently related to IR in not only nondiabetic participants but also T2DM patients [34].

Stefan et al. [35] agreed with us, as they showed in a 7year follow-up study significant associations among 
fetuin-A and extended risk for DM, specifically in people with increased plasma glucose levels within the nondiabetic variety.

We agreed with Takata et al. [36] who have shown that high concentrations of glucose induced transactivation of the $A H S G$ gene, which encodes fetuin-A protein, expression in cultured human hepatoma cells, and such finding approved the relation between high levels of fetuin-A and the development of DM.

This correlated also with Ishibashi et al. [37] who found that serum fetuin-A concentrations were significantly associated with IR. They confirmed that the serum fetuin-A level is independently associated with IR in Japanese patients.

Kröger et al. [38] disagreed with us as they concluded although there was mechanistical evidence for an effect of fetuin-A on insulin sensitivity and secretion, their study did not support a strong, relevant relationship between circulating fetuin-A and diabetes risk in the general population.

Our results did not coincide with Eleftheriadou et al. [39] who showed that plasma fetuin-A levels were lower in patients with T2DM.

In contrast to our study, Eraso et al. [40] showed that circulating fetuin-A was lower in T2DM with vascular complications than diabetes controls. Similar disagreement was shown by Roos et al. [41] who found that lower fetuin-A levels seem to be associated with prevalent macrovascular disease in T2DM.

Mori et al. [42] disagreed with us as they evaluated serum fetuin-A in T2DM and nondiabetic individuals and did no longer discover any distinction between groups in terms of fetuin- $A$ and any significant correlation between IR and fetuin-A.

Our results did not coincide with Yilmaz et al. [43] who observed significantly lower fetuin-A levels in the diabetic group owing to urinary loss of fetuin-A; moreover, Fethiye and colleagues disagreed with us as they found that lower fetuin-A levels in the T2DM group compared with the control group [44].

In this work, there was a significant increase in the mean levels of TAG, cholesterol, and LDL-c in diabetic patients with retinopathy group and diabetic patients with nephropathy group than the control group, and there was a significant decrease in the mean levels of HDL-c in the diabetic patients with retinopathy group and the diabetic with nephropathy group than the diabetic group and the control group. There was a significant positive correlation between fetuin-A, TAG, cholesterol, and LDL-c in the diabetic and the diabetic with retinopathy groups. In the diabetic with nephropathy group, there was a significant positive correlation between fetuin-A, TAG, and LDL-c. There was a significant negative correlation between fetuin-A and HDL-c in the diabetic group. We also found there was a significant positive correlation between fetuin-A and some clinical and metabolic parameters such as blood pressure, BMI, waist circumference, and $\mathrm{W} / \mathrm{H}$ ratio in all studied groups.

Zhou et al. agreed with us because they showed that higher serum fetuin-A levels in obese T2DM patients compared with nonobese patients and obese normal glucose tolerance patients, which supports the hypothesis that fetuin-A may be a bridge connecting obesity and obesity-related T2DM [45].

The study by Reinehr et al. [46] coincided with ours, as it concluded that the increase of fetuin-A levels in obese adolescents with T2DM supports the hypothesis that fetuin-A is involved in the pathogenesis of T2DM, because this hepatokine leads to IR.

Stępień and colleagues showed similar results who aimed to estimate the association between anthropometric obesity parameters, and HOMA-IR in obese nondiabetic insulin-sensitive and insulinresistant patients and explained those by inhibition of the insulin receptor by fetuin-A may lead to increased lipolysis and efflux of free fatty acids from adipose tissue. This may, in turn, lead to increased production of apolipoprotein B-containing lipoproteins (very-low density lipoprotein) [47]. Furthermore, hypertriglyceridemia may lead to a decrease in the cholesterol content of HDL, which may enhance HDL clearance from the circulation, thereby potentially leading to the atherogenic lipid profile observed in this study [48].

In accordance with our results, Ayako and colleagues found a significant association between serum fetuin- $A$ and atherogenic lipid profile in individuals without any coronary artery disease. They explained that another factor may promote the elevation in fetuin-A and LDL-c levels; for example, transcriptional factors that regulate cholesterol homeostasis could be involved in the regulation of hepatic synthesis of fetuin-A [37].

We agreed with $\mathrm{Xu}$ et al. [49] who found that serum fetuin-A is correlated with MetS in middle-aged and 
elderly Chinese population. Ix et al. [10] agreed with us as they reported an association between human fetuin$\mathrm{A}$ and the MetS nondiabetic outpatients with coronary artery disease.

In contrast to our study, Ayako and colleagues, Eraso and colleagues, Roos and colleagues, and Fethiye and colleagues found that fetuin-A levels did not correlate with metabolic parameters in their patients with T2DM with prevalent late complications. They explained their results by exclusion of patients with chronic diseases as CAD from their study which could explain the higher prevalence of MetS in the previous studies $[40,41,44]$.

In our study, there was a high significant increase seen in the mean levels of insulin, HOMA-IR, and fetuin-A in the diabetic with nephropathy group versus other groups. There was a significant positive correlation between fetuin-A and 24-h urinary protein in the diabetic with nephropathy group.

As previously known, there was a direct correlation between adiponectin levels and overt proteinuria [8]. Fetuin-A suppresses mRNA encoding adiponectin in cultured human adipocytes, and treatment of wild-type mice with fetuin-A lowered serum adiponectin levels [50]. Lower adiponectin levels reduce AMP-activated protein kinase in podocytes to promote foot process effacement and albuminuria [51]. All these previous reports could explain the relation between fetuin- $\mathrm{A}$ and albuminuria.

In accordance with our results, Inoue et al. [52] showed that urinary excretion of fetuin-A significantly increased during the progression of albuminuria, and they concluded that urinary fetuin-A was demonstrated as a risk factor for both microalbuminuria and reduction of glomerular filtration rate in diabetic nephropathy.

Other studies were in accordance with our results about the correlation between serum levels of fetuin-A and 24-h urinary protein. Mehrotra et al. [53] showed that Latinos with diabetic nephropathy not undergoing maintenance dialysis have significantly higher serum fetuin-A levels when compared with diabetic control patients.

In contrast to these results, Yilmaz et al. [43] observed significantly lower fetuin-A levels in the diabetic group and a negative correlation with proteinuria and expressed that urinary loss of fetuin-A, which is a vasoprotective protein, may contribute to increased cardiovascular disease risk in these patients. Fethiye and colleagues disagreed with us as they stated that
fetuin-A levels were not different according to the presence of proteinuria [44]. In contrast to our results, Eraso et al. [40] showed that fetuin-A serum levels were not associated with 24-h urinary albumin excretion in patients with early diabetic nephropathy.

This study showed that there was a nonsignificant increase in the mean levels of fetuin-A in patients with DR compared with diabetic patients without microvascular complications.

In contrast to our results, Yilmaz and colleagues suggested an association between fetuin-A levels and DR stage. In diabetic patients, the risk of retinopathy development increases with higher fetuin-A values. Fetuin-A may play an important role in the pathophysiology and progression of DR [54].

We disagreed with Zhao et al. [55] as they suggested the occurrence and severity of DR is correlated with serum and vitreous fetuin-A concentrations.

\section{Conclusion}

The study proved that there were high levels of fetuinA in patients with T2DM which were associated with IR and metabolic parameters. The results suggested that higher levels of fetuin-A were associated with the diabetic nephropathy. Fetuin-A may be used as a marker for microvascular complications in T2DM, especially the diabetic nephropathy group. Antifetuin agents may be used to delay diabetic microvascular complications.

\section{Financial support and sponsorship}

Nil.

\section{Conflicts of interest}

There are no conflicts of interest.

\section{References}

1 Standards of Medical Care in Diabetes. Summary of revisions. Diabetes Care 2016; 39(Suppl 1):S4-S5.

2 International Diabetes Federation. Diabetes atlas. 7th ed. Brussels, Belgium: International Diabetes Federation; 2015

3 Scirica BM. Use of biomarkers in predicting the onset, monitoring the progression, and risk stratification for patients with type 2 diabetes mellitus. Clin Chem 2017; 63:186-195

4 Kim HC, Greenland P, Rossouw JE, Manson JE, Cochrane BB, Lasser NL, et al. Multimarker prediction of coronary heart disease risk: The Women's Health Initiative. J Am Coll Cardiol 2010; 55:2080-2091.

5 Maruo S, Mori K, Motoyama K, Nakamura M, Kawarabayashi R, Kakutani Y, et al. Correlation analysis of monocyte subsets and insulin resistance considering fetuin-A involvement in patients with type 2 diabetes. Clin Transl Med 2018; 7:9.

6 Denecke B, Graber S, Schafer C, Heiss A, Woltje M, Jahnen-Dechent W. Tissue distribution and activity testing suggest a similar but not identical function of fetuin-B and fetuin-A. Biochem J 2003; 376:135-145.

7 Schafer C, Heiss A, Schwarz A, Westenfleld R, Ketteler M, Floege J, et al. The serum protein alpha 2-Heremans-Schmid glycoprotein/fetuin-A is a systemically acting inhibitor of ectopic calcification. J Clin Invest 2003; 112: 357-366. 
8 Hennige AM, Staiger $\mathrm{H}$, Wicke C, Machicao F, Fritsche A, Haring HU, Stefan N. Fetuin-A induces cytokine expression and suppresses adiponectin production. PLoS ONE 2008; 3:e1765.

9 Srinivas PR, Wagner AS, Reddy LV, Deutsch DD, Leon MA, Goustin AS, Grunberger G. Serum alpha 2-HS-glycoprotein is an inhibitor of the human insulin receptor at the tyrosine kinase level. Mol Endocrinol 1993; 7:1445-1455.

10 Ix JH, Shlipak MG, Brandenburg VM, Ali S, Ketteler M, Whooley MA. Association between human fetuin-A and the metabolic syndrome. Data from the Heart and Soul Study. Circulation 2006; 113:1760-1767.

11 Ix JH, Wassel CL, Kanaya AM, Vittinghoff E, Johnson KC, Koster A, et al. Fetuin-A and incident type 2 diabetes mellitus in older persons. JAMA 2008; 300: 182-188.

12 Ketteler M, Bongartz P, Westenfeld R, Wildberger JE, Mahnken AH, Bohm $\mathrm{R}$, et al. Association of low fetuin-A (AHSG) concentrations in serum with cardiovascular mortality in patients on dialysis: a cross-sectional study. Lancet 2003; 361:827-833.

13 Weikert C, Stefan N, Schulze MB, Pischon T, Berger K, Joost HG, et al. Plasma fetuin-A levels and the risk of myocardial infarction and ischemic stroke. Circulation 2008; 118:2555-2562.

14 American Diabetes Association. Standards of medical care in diabetes. Diabetes Care 2009; 32(Suppl 1):S13-S61.

15 Keys A, Fidanza F, Karvonen MJ, Kimura N, Taylor HL. Indices of relative weight and obesity. J Chronic Dis 1972; 25:329-343.

16 Shintani Y, Fujie H, Miyoshi H, Tsutsumi T, Tsukamoto K, Kimura S, et al. Hepatitis $C$ virus infection and diabetes: direct involvement of the virus in the development of insulin resistance. Gastroenterology 2004; 126:840-848.

17 Flegg HM. An investigation of serum cholesterol by an enzymatic method. Ann Clin Biochem 1973; 10:79.

18 Buccolo G, David H. Quantitative determination of serum triglycerides by use of enzymes. Clin Chem 1973; 19:467-482.

19 Finley PR. Determination of high density lipoprotein (HDL) cholesterol in serum or plasma. Clin Chem 1978; 24:931.

20 Friedewald WT, Levy RI, Fredrickson DS. Estimation of the concentration of low-density lipoprotein cholesterol in plasma, without use of the preparative ultracentrifuge. Clin Chem 1972; 18:499-502.

21 Bartels H, Böhmer M, Heierli C. Serum creatinine determination without protein precipitation. Clin Chim Acta 1972; 37:193-197.

22 Rose CFM. The estimation of urea by urease methods in fluoride blood. $\mathrm{Br} \mathrm{J}$ Exp Pathol 1933; 14:339-342.

23 Varley $\mathrm{H}$, Gowenlock $\mathrm{AH}$. Collection of specimens and some general techniques. Practical clinical biochemistry: general topics and commoner tests. 5th ed. London: Butterworth-Heinemann Ltd; 1980. 379-380

24 Stevens LA, Levey AS. Current status and future perspectives for CKD testing. Am J Kidney Dis 2009; 53: S17-S26.

25 Vionnet N, Hani EH, Dupont S, Gallina S, Francke S, Dotte S, et al. Genome wide search for type 2 diabetes-susceptibility genes in French whites: evidence for a novel susceptibility locus for early-onset diabetes on chromosome 3q27-qter and independent replication of a type 2- diabetes locus on chromosome 1q21-q24. Am J Hum Genet 2000; 67:1470-1480.

26 Lorenzo C, Wagenknecht LE, D’Agostino RB Jr, Rewers MJ, Karter AG, Haffner SM. Insulin resistance, $\beta$-cell dysfunction, and conversion to type 2 diabetes in a multiethnic population. Diabetes Care 2010; 33:67-72.

27 Guo VY, Cao B, Cai C, Cheng KK, Cheung BMY. Fetuin-A levels and risk of type 2 diabetes mellitus: a systematic review and meta-analysis. Acta Diabetol 2018; 55:87-98

28 Sujana C, Huth C, Zierer A, Meesters S, Sudduth-Klinger J, Koenig W, et al. Association of fetuin-A with incident type 2 diabetes: results from the MONICA/KORA Augsburg study and a systematic meta-analysis. Eur $\mathrm{J}$ Endocrinol 2018; 178:389-398.

29 Pinnaduwage L, Ye C, Hanley AJ, Connelly PW, Sermer M, Zinman B, Retnakaran R. Changes over time in hepatic markers predict changes in insulin sensitivity, beta-cell function and glycemia. J Clin Endocrinol Metabol 2018; 103:2018-00306.

30 Roshanzamir F, Miraghajani M, Rouhani MH, Mansourian M, Ghiasvand R, Safavi SM. The association between circulating fetuin-A levels and type 2 diabetes mellitus risk: systematic review and meta-analysis of observational studies. J Endocrinol Invest 2107 41:33-47.

31 Yin L, Cai W-J, Zhu L-Y, Li J, Su X-H, Wang X-L, et al. Association of plasma Fetuin-A and clinical characteristics in patients with new-onset type 2 diabetes mellitus. Int J Clin Exp Med 2015; 8:991-999.

32 Ou HY, Lu FH, Wu HT, Hung HC, Wu JS, Yang YC, Chang CJ. Both diabetes and fetuin-A are independently associated with increased risk of arterial stiffness. Clin Chim Acta 2015; 445:133-138.
33 lyidir OT, Degertekin CK, Yilmaz BA, Altinova AE, Toruner FB, Bozkurt N, et al. Serum levels of fetuin $A$ are increased in women with gestational diabetes mellitus. Arch Gynecol Obstet 2015; 291:933-937.

34 Song $\mathrm{A}, \mathrm{Xu} \mathrm{M}, \mathrm{Bi} \mathrm{Y}, \mathrm{Xu} \mathrm{Y}$, Huang $\mathrm{Y}$, Li M, et al. Serum fetuin-A associates with type 2 diabetes and insulin resistance in Chinese adults. PLoS ONE 2011; 6:e19228.

35 Stefan N, Fritsche A, Weikert C, Boeing H, Joost HG, Häring HU, Schulze MB. Plasma fetuin-A levels and the risk of type 2 diabetes. Diabetes 2008; 57:2762-2767.

36 Takata H, Ikeda $\mathrm{Y}$, Suehiro $\mathrm{T}$, Ishibashi A, Inoue M, Kumon $\mathrm{Y}$, Terada $\mathrm{Y}$. High glucose induces transactivation of the alpha2-HS glycoprotein gene through the ERK1/2 signaling pathway. J Atheroscler Thromb 2009; 16:448-456.

37 Ishibashi A, Ikeda Y, Ohguro T, Kumon Y, Yamanaka S, Takata H, et al. Serum fetuin-A is an indeoendent marker of insulin resistance in Japanese men. J Atheroscler Thromb 2010; 17:925-933.

38 Kröger J, Meidtner K, Stefan N, Guevara M, Kerrison ND, Ardanaz E, et al. Circulating fetuin-a and risk of type 2 diabetes: a mendelian randomization analysis. Diabetes 2018; [Epub ahead of print]

39 Eleftheriadou I, Grigoropoulou P, Kokkinos A, Mourouzis I, Perrea D, Katsilambros $\mathrm{N}$, et al. Association of plasma fetuin-a levels with peripheral arterial disease and lower extremity arterial calcification in subjects with type 2 diabetes mellitus. J Diabetes Complications 2017; 31:599-604.

40 Eraso LH, Ginwala N, Qasim AN, Mehta NN, Dlugash R, Kapoor S, et al. Association of lower plasma fetuin-a levels with peripheral arterial disease in type 2 diabetes. Diabetes Care 2010; 33:408-410.

41 Roos M, Oikonomou D, von Eynatten M, Luppa PB, Heemann U, Lutz J, et al. Associations of fetuin-A levels with vascular disease in type 2 diabetes patients with early diabetic nephropathy. Cardiovasc Diabetol 2010; 9:48.

42 Mori K, Emoto M, Yokoyama H, Araki T, Teramura M, Koyama H, et al. Association of serum fetuin-A with insulin resistance in type 2 diabetic and non-diabetic subjects. Diabetes Care 2006; 29:468.

43 Yilmaz MI, Saglam M, Qureshi AR, Carrero JJ, Caglar K, Eyileten T, et al. Endothelial dysfunction in type-2 diabetics with early diabetic nephropathy is associated with low circulating adiponectin. Nephrol Dial Transplant 2008; 23:1621-1627.

44 Zhou ZW, Ju HX, Sun MZ, Chen HM, Fu QP, Jiang DM. Serum fetuin-A levels in obese and non-obese subjects with and without type 2 diabetes mellitus. Clin Chim Acta 2018; 476:98-102.

45 Gunduz FO, Yildirmak ST, Temizel M, Faki Y, Cakmak M, Durmuscan M, Sezgin F. Serum visfatin and fetuin-a levels and glycemic control in patients with obese type 2 diabetes mellitus. Diabetes Metab J 2011; 35:523-528.

46 Reinehr T, Karges B, Meissner T, Wiegand S, Fritsch M, Holl RW, Woelfle J. Fibroblast growth factor 21 and fetuin-a in obese adolescents with and without type 2 diabetes. J Clin Endocrinol Metab 2015; 100:3004-3010.

47 Stę pien M, Wlazeł RN, Paradowski M, Banach M, Rysz M, Misztal M, Rysz J. Serum concentrations of adiponectin, leptin, resistin, ghrelin and insulin and their association with obesity indices in obese normo- and hypertensive patients - pilot study. Arch Med Sci 2012; 8:431-436.

48 Lewis GF, Uffe Iman KD, Szeto LW, Weller B, Steiner G. Interaction between free fatty acids and insulin in the acute control of very lowdensity lipoprotein production in humans. J Clin Invest 1995; 95:158-166.

$49 \mathrm{Xu}$ Y, Xu M, Bi Y, Song A, Huang Y, Liu Y, et al. Serum fetuin-A is correlated with metabolic syndrome in middle-aged and elderly Chinese. Atherosclerosis 2011; 216:180-186.

50 Yang J, Maika S, Craddock L, King JA, Liu ZM. Chronic activation of AMPactivated protein kinase-alpha1 in liver leads to decreased adiposity in mice. Biochem Biophys Res Commun 2008; 370:248-253.

51 Sharma K, Ramachandrarao S, Qiu G, Usui HK, Zhu Y, Dunn SR, et al. Adiponectin regulates albuminuria and podocyte function in mice. J Clin Invest 2008; 118:1645-1656.

52 Inoue K, Wada J, Eguchi J, Nakatsuka A, Teshigawara S, Murakami K, et al. Urinary fetuin-A is a novel marker for diabetic nephropathy in type 2 diabetes identified by lectin microarray. PLoS ONE 2013; 8:e77118.

53 Mehrotra R, Westenfeld R, Christenson P, Budoff M, Ipp E, Takasu J, et al. Serum fetuin $A$ in non-dialyzed patients with diabetic nephropathy: relationship with coronary artery calcification. Kidney Int 2005; 67:1070-1077.

54 Yilmaz A, Yilmaz T,, Gunay M. Elevated serum fetuin-A levels are associated with grades of retinopathy in type 2 diabetic patients. Int Ophthalmol 2017; 37:113-117.

55 Zhao C, Hou J, Wang S, Jiang R. Relation of serum and vitreous concentrations of fetuin-a with diabetic retinopathy. Med Sci Monit 2015; $21: 1839-1842$ 